\title{
On the independence of hydrogen production from methanogenic suppressor in olive mill wastewater
}

\author{
M.R. Gonçalves, J.C. Costa, M.A. Pereira, A.A. Abreu*, M.M. Alves \\ Institute for Biotechnology and Bioengineering, Centre of Biological Engineering, University of Minho, \\ 4710-057 Braga, Portugal
}

\section{A R T I C L E I N F O}

\section{Article history:}

Received 20 August 2013

Received in revised form

18 November 2013

Accepted 9 February 2014

Available online 11 March 2014

\section{Keywords:}

Biohydrogen

Biomethane

Homoacetogenesis

Olive oil mill effluent

Methanogenic suppressor

Anaerobic digestion

\begin{abstract}
A B S T R A C T
Anaerobic degradation of olive mill wastewater (OMW) at concentrations ranging from 2 to $100 \mathrm{~g} / \mathrm{L}$ of chemical oxygen demand (COD) was assessed in batch assays. Methane was the main final product obtained for the lower concentrations tested. For $25 \mathrm{~g} C O D / L, \mathrm{H}_{2}$ was temporarily produced, albeit $\mathrm{H}_{2}$ depletion occurred, likely due to homoacetogenesis, since acetate was formed concomitantly. Hydrogen was produced and accumulated permanently in the assays containing $50 \mathrm{~g}$ COD/L of OMW. Methanogenesis and homoacetogenesis were naturally inhibited, suggesting that hydrogen recovery from OMW can be performed without the addition of methanogenic suppressors such as 2bromoethanosulfonate. This fact opens new perspectives for the utilization of high OMW concentrations in a two-stage valorisation process combining biohydrogen and biomethane production.
\end{abstract}

Copyright $\odot$ 2014, Hydrogen Energy Publications, LLC. Published by Elsevier Ltd. All rights reserved.

\section{Introduction}

Olive mill wastewater (OMW) is a complex effluent obtained from the traditional press and the continuous three-phase mills of olive oil production. Large amounts of OMW are generated every year and yet there are no feasible solutions to its treatment [1]. The production of biofuels (methane or hydrogen) from OMW is a promising solution for the treatment and valorisation of this pollutant [2]. However, there are still some problems associated with both processes.

Anaerobic digestion of raw OMW has been reported as a difficult process mainly due to their intrinsic characteristics, such as acid $\mathrm{pH}$, high organic loads and the presence of complex and toxic compounds (lipids and phenolic compounds) [1]. Anaerobic batch experiments have shown that high concentrations of OMW, such as $50 \mathrm{~g} / \mathrm{L}$ chemical oxygen demand (COD), may lead to the inhibition of the microbial consortium [3]. The high concentration of raw OMW (130 g COD/L) has led researchers to use highly diluted streams ( $5 \mathrm{~g} \mathrm{COD/L}$ ) during the start-up of continuous anaerobic reactors, whereas $45-50 \mathrm{~g}$ COD/L of OMW was only used after one year of operation [4].

Hydrogen production from OMW has been performed by dark and photofermentation [5-8]. One of the main issues concerning hydrogen production through anaerobic processes is to assure that hydrogen-consuming microorganisms' are inhibited, and the activity of hydrogen-producing microorganisms is preserved and stimulated. Under anaerobic conditions, hydrogen is used mainly by hydrogenotrophic

\footnotetext{
* Corresponding author. Tel.: +351 253604400; fax: +351 253604429.

E-mail addresses: angela_abreu@deb.uminho.pt, abreu.angela@gmail.com (A.A. Abreu). http://dx.doi.org/10.1016/j.ijhydene.2014.02.056

0360-3199/Copyright @ 2014, Hydrogen Energy Publications, LLC. Published by Elsevier Ltd. All rights reserved.
} 
methanogens to produce methane and by homoacetogenic bacteria to produce acetate [9]. Sludge pre-treatment with heat $[10,11]$ and the addition of chemicals such as 2bromoethanesulfonate (BES) [12,13] and chloroform [14] have been used to inhibit $\mathrm{H}_{2}$ utilizers during the anaerobic degradation of wastewaters such as OMW and palm oil mill effluent. Alternatively, pure cultures have been used to produce hydrogen from these types of effluents [15]. Nevertheless, these strategies increase the overall cost of the process. In addition, chemical and heat treatments have usually a short time effect on methanogeneses and are not effective to prevent homoacetogenesis [16,17]. So far, there are no studies correlating OMW concentration with hydrogen production without applying strategies to inhibit $\mathrm{H}_{2}$ utilizers.

Preliminary studies carried out in our research group (not published) suggested that hydrogen is selectively produced at high OMW concentration, in detriment of methane, without the need of applying strategies to inhibit $\mathrm{H}_{2}$ utilizers. In this vein, the main objective of this work is to get more insights on the influence of OMW concentration on biohydrogen production and on the requirement of a methanogenic inhibitor.

\section{Material and methods}

Anaerobic batch experiments were carried out at different initial OMW concentrations, ranging from 2 to $100 \mathrm{~g}$ chemical oxygen demand per litter (COD/L), in the presence and absence of a methanogenic suppressor 2-bromoethane sulfonate (BES) - an analogue of coenzyme $M$ in methanogens and inhibitor of methane-producing Archaea. These experiments were performed to evaluate the influence of the substrate concentration on $\mathrm{H}_{2}$ and $\mathrm{CH}_{4}$ production and to assess the need of a methanogenic inhibitor to promote $\mathrm{H}_{2}$ production.

\subsection{Inoculum and substrate}

The anaerobic suspended sludge used in the batch experiments was obtained from a domestic wastewater treatment plant. The specific methanogenic activity of the sludge was $<0.05$ and $0.26 \pm 0.01 \mathrm{~g} \mathrm{COD}^{-\mathrm{CH}_{4}(\mathrm{STP})} \mathrm{gVS}^{-1} \mathrm{~d}^{-1}$ for acetate and $\mathrm{H}_{2} / \mathrm{CO}_{2}(80 / 20 \mathrm{v} / \mathrm{v})$, respectively. The OMW was obtained from a three-phase continuous olive oil extraction process (Amarante, Portugal) and stored at $-20{ }^{\circ} \mathrm{C}$ for further utilization. OMW was characterized and the values obtained are summarized in Table 1.

\subsection{Experiment set-up}

Batch assays were performed in closed vials with volumes of 70 and $160 \mathrm{~mL}$. The working volume was $20 \mathrm{~mL}$. The sludge was added to the vials at a final concentration of around $3 \mathrm{~g}$ volatile suspended solids per litter (VSS/L). The basal medium used in all batch experiments was made up with demineralised water and sodium bicarbonate $(3 \mathrm{~g} / \mathrm{L})$ and the $\mathrm{pH}$ was adjusted to 7.0. The OMW, previously adjusted to $\mathrm{pH}$ 7.0, was diluted at different final concentrations of 2, 10, 25, 50 , and $100 \mathrm{~g} \mathrm{COD/L}$. The vials were flushed with $\mathrm{N}_{2} / \mathrm{CO}_{2}$ $(80: 20 \mathrm{~V} / \mathrm{v})$ and finally the medium was reduced with
Table 1 - Olive mill wastewater (OMW) characterization.

\begin{tabular}{lc} 
Parameter & $\mathrm{OMW}^{\mathrm{a}}$ \\
\hline $\mathrm{pH}$ & $4.7 \pm 0.1$ \\
Total COD $(\mathrm{g} / \mathrm{L})$ & $130.1 \pm 7.4$ \\
Total Solids $(\mathrm{g} / \mathrm{L})$ & $75.5 \pm 3.1$ \\
Total Nitrogen (mg/L) & $460.0 \pm 53.2$ \\
Total Phenols (Gallic acid, g/L) & $4.3 \pm 0.4$ \\
Oil and Grease (g/L) & $13.6 \pm 1.5$ \\
Total free-long chain fatty acids (g COD/L) & $6.2 \pm 3.8$ \\
$\%$ C18:1 & $78.1 \pm 10.9$ \\
\hline a Data expressed as an average \pm error (95\% confidence). \\
\hline
\end{tabular}

$\mathrm{Na}_{2} \mathrm{~S} .9 \mathrm{H}_{2} \mathrm{O}$ at final concentration of $1 \mathrm{mM}$. The batch experiments were performed in the presence $(15 \mathrm{mM})$ and absence of BES. The vials were placed on a rotary shaker (100 rpm) and incubated at $37{ }^{\circ} \mathrm{C}$. The batch experiments performed with OMW concentrations of 2, 10 and $25 \mathrm{~g}$ COD/L were done in duplicate. $\mathrm{pH}$, methane and hydrogen were determined along the experiment time. For the batch assay containing $25 \mathrm{~g} \mathrm{COD/L}$, volatile fatty acids (VFAs) were also analysed. Batch experiments with 50 and $100 \mathrm{~g}$ COD/L of OMW were carried out in quadruplicate, since the results variability is high for these substrate concentrations. In this case, VFAs and $\mathrm{pH}$ were only measured at the end of the experiment. Methane and hydrogen accumulated in the vials headspace were measured along the experiments. The measured values of each gas were corrected to standard temperature and pressure (STP) conditions. The amount of methane produced was converted to equivalent $\mathrm{COD}\left(\mathrm{mg} \mathrm{COD}-\mathrm{CH}_{4}\right)$, considering the theoretical biochemical methane potential $\left(350 \mathrm{~L} \mathrm{CH}_{4}\right.$ $\left.\mathrm{kg}^{-1} \mathrm{COD}\right)$.

\subsection{Analytical methods}

Total chemical oxygen demand (COD), total solids (TS), total phenols and biogas were determined as described in previous studies [3,4]. VFAs analysis has been described previously [18].

\section{Results and discussion}

The initial production of hydrogen and methane from OMW at concentrations ranging from 2 to $100 \mathrm{~g} \mathrm{COD/L}$, in the presence and absence of a methanogenic inhibitor (BES), is represented in Fig. 1.

In BES-free vials, the highest methane production (49 $\mathrm{mg}$ COD-CH ) was achieved with 2 g COD/L of OMW (Fig. 1(a)) in 19 days, representing a biodegradability of $81 \%$. Lower methanisation was obtained for OMW concentrations of 10 and $25 \mathrm{~g}$ $\mathrm{COD} / \mathrm{L}$, in a similar time range, and no methane production was observed in batch experiments with 50 and $100 \mathrm{~g}$ COD/L. A lag-phase of 7 days was observed in the batch experiment performed with $25 \mathrm{~g}$ COD/L.

Regarding hydrogen production (Fig. 1(b)), the accumulation of $\mathrm{H}_{2}$ was only verified in batch experiments with $50 \mathrm{~g}$ COD/L. A production of $0.53 \mathrm{mmol} \mathrm{H}_{2}$ was attained after 3 days and it was practically stable until the end of experiment (32 days). After day 1, $0.3 \mathrm{mmol}$ of hydrogen was produced, with 

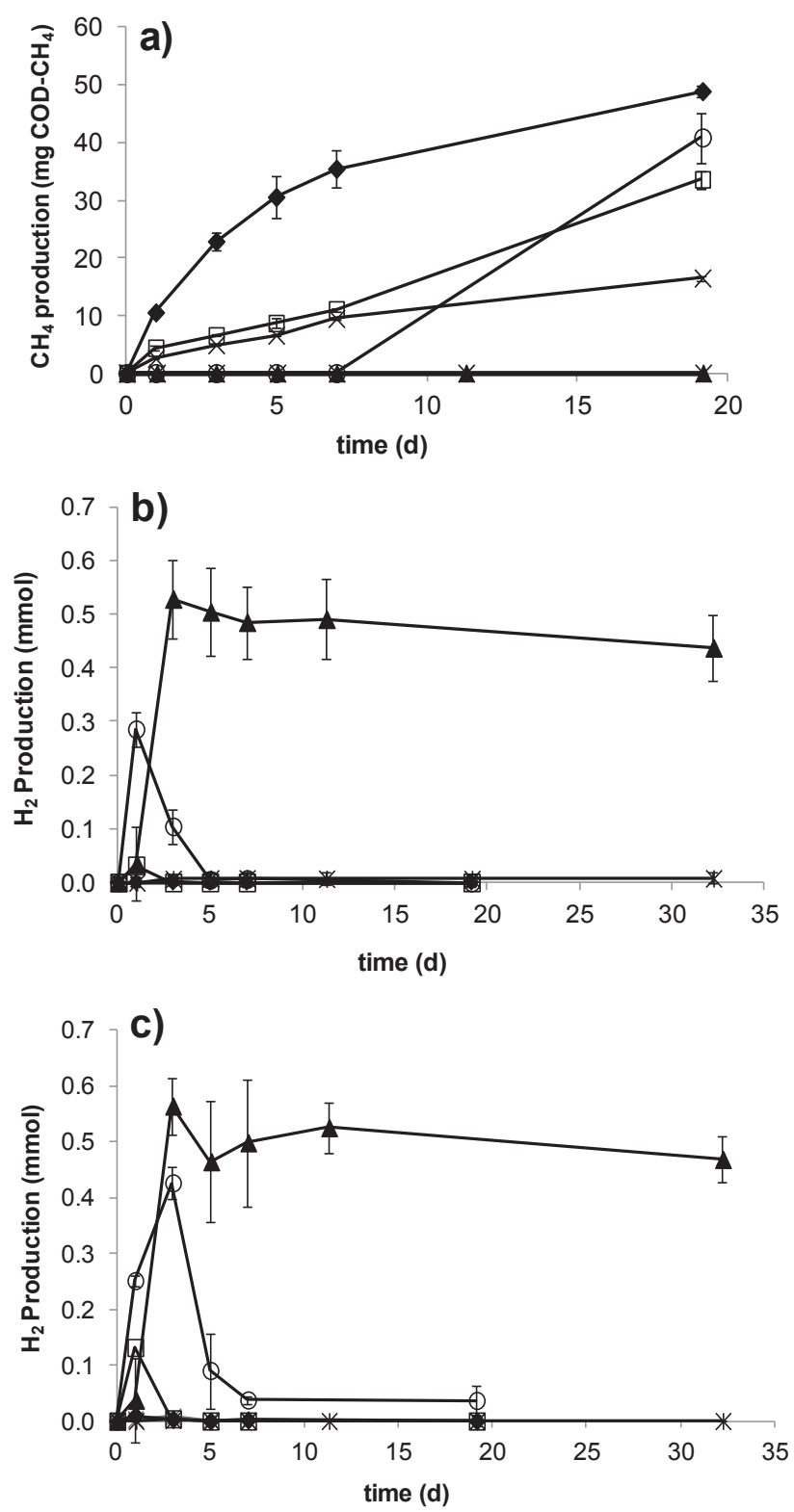

Fig. 1 - Methane (a) and hydrogen (b) production in BES-free vials and hydrogen production in the presence of BES (c) at different OMW concentrations. $f \times 1$ blank; fx2 2 g COD/L; fx3 10 g COD/L; fx4 25 g COD/L; fx5 50 g COD/L; fx6 100 g COD/L.

$25 \mathrm{~g}$ COD/L OMW. However, hydrogen depletion occurred afterwards and at day 5 was already absent (Fig. 1(b)). Hydrogen was detected at residual concentrations in the batch experiments performed with $100 \mathrm{~g}$ COD/L.

In the presence of BES, as expected, methane was not detected at any OMW concentration. This compound inhibits methanogenic activity [11], promoting $\mathrm{H}_{2}$ formation. In the present study, the presence of BES did not improve significantly the hydrogen production from OMW. Hydrogen production values obtained with and without BES were similar (Fig. 1(b) and (c)). The main difference was verified at $25 \mathrm{~g} \mathrm{COD} / \mathrm{L}$, in which a higher $\mathrm{H}_{2}$ production was attained (0.4 mmol). Nevertheless, the hydrogen content decreased afterwards, similarly to the BES-free trials.
Although methanogenesis was observed in BES free-vials with substrate concentrations of 2, 10 and $25 \mathrm{~g} \mathrm{COD/L,}$ methane was not produced for substrate concentrations equal or higher than $50 \mathrm{~g}$ COD/L. These results corroborate previous findings wherein methane production was inhibited in the presence of $50 \mathrm{~g}$ COD-OMW L ${ }^{-1}$, even using an acclimated sludge [3]. In the present work, it was disclosed that hydrogen is selectively produced at high OMW concentrations (25 and $50 \mathrm{~g} \mathrm{COD/L}$ ), independently of the BES presence. Moreover, at an OMW concentration of $50 \mathrm{~g}$ COD/L, hydrogen consumption by both homoacetogenic bacteria and hydrogenotrophic methanogens was blocked, which is a new finding that opens the possibility of using OMW for direct $\mathrm{H}_{2}$ production.

The results obtained with $25 \mathrm{~g}$ COD/L in the presence of BES suggested that $\mathrm{H}_{2}$ was depleted by homoacetogenic bacteria, since methanogenic archaea were inhibited (methane was not detected).

The VFAs and $\mathrm{pH}$ were determined along the batch experiments performed with $25 \mathrm{~g}$ COD/L in order to explore this hypothesis. Independently of the presence of a methanogenic suppressor, hydrogen and acetate were the main intermediates initially detected (Fig. 2(a) and (b)). After this initial phase, hydrogen was rapidly consumed and acetate concentration rose up to a maximum of 1.52 and $1.03 \mathrm{~g} / \mathrm{L}$ at day 5 , in the absence and in the presence of BES, respectively. In a subsequent phase, acetate depletion accompanied by methane production was observed for the BES-free vials (Fig. 2(a)) whereas in the assays with BES acetate accumulated consistently (Fig. 2(b)). Besides acetate, butyrate was the main VFA produced, reaching a maximum of $1.36 \mathrm{~g} / \mathrm{L}$ and $1.16 \mathrm{~g} / \mathrm{L}$, in the absence and in the presence of BES, correspondingly. At the end of the experiment, propionate was also present with concentrations of 0.33 and 0.30 g/L (Fig. 2(c) and (d)).

Acetogenesis only proceeds at low hydrogen partial pressures to favour the thermodynamics of the reactions [19]. In this study, acetate was consumed (acetoclastic methanogenesis) only after hydrogen depletion. Moreover, during the depletion of hydrogen, methane was not detected and acetate was formed concomitantly, indicating that hydrogenotrophic methanogenesis was unfavourable compared to homoacetogenesis. $\mathrm{Xu}$ et al. [10] reported that homoacetogenesis was stimulated under suppressed methanogenesis (with BES) during the mesophilic anaerobic digestion of sludge. Luo et al. [17] also reported higher homoacetogenic activity when methanogenesis was fully inhibited under mesophilic conditions. The results obtained in the present work sustain the hypothesis that homoacetogenesis can be the main pathway for $\mathrm{H}_{2}$ depletion, in a mesophilic anaerobic consortium treating OMW, even when methanogenesis was not suppressed by BES. The inhibition of hydrogenotrophic methanogens can be due to a drop in $\mathrm{pH}(<6.0)$ or to the presence of toxic compounds [20]. However, in this case $\mathrm{pH}$ was always equal or above 6.0. The presence of toxic compounds in olive mill wastewaters is well described, being emphasized the lipidic and phenolic compounds as the main toxic and/or recalcitrants [21,22].

Hydrogen was considerably produced and accumulated in batch experiments with OMW concentration of $50 \mathrm{~g}$ COD/L. Soluble fermentation products and hydrogen partial pressure were determined at the end of the experiments (Table 2). It 
a)

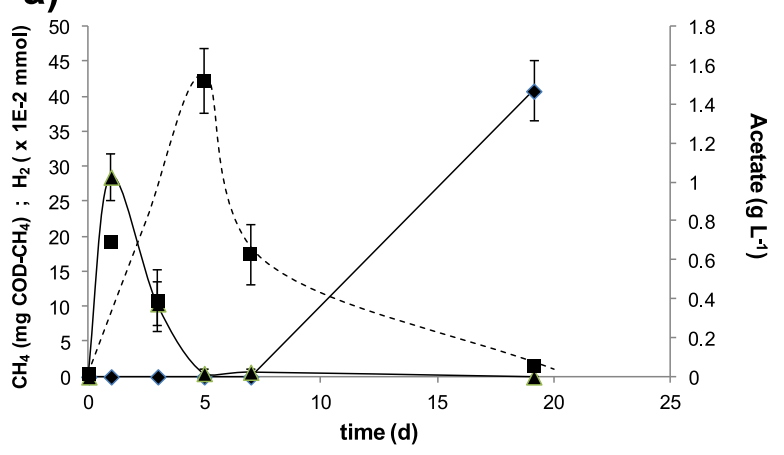

b)
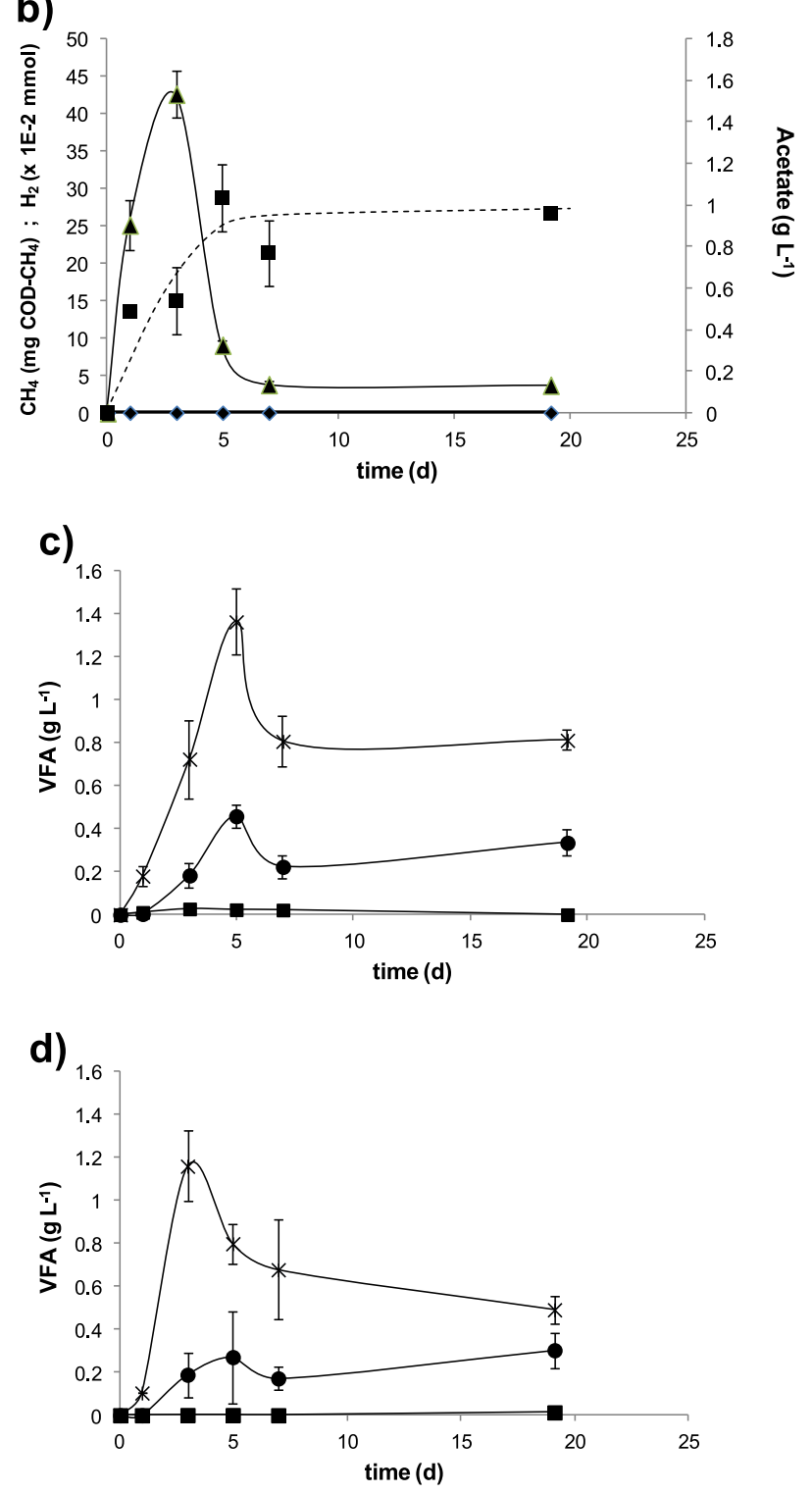

Fig. 2 - Acetate (g/L), methane (mg COD- $\left.\mathrm{CH}_{4}\right)$, hydrogen $(\times 1 \mathrm{E}-2 \mathrm{mmol})$ and volatile fatty acids (VFA, g/L) production throughout the batch experiment with $25 \mathrm{~g}$ COD-OMW L ${ }^{-1}$, in the absence $(a, c)$ and in the presence $(b, d)$ of BES. $f \times 7$ Acetate; $\mathrm{fx} 5 \mathrm{H}_{2}$; $\mathrm{fx} 2 \mathrm{CH}_{4}$; fx1 n-Butyrate; fx8 Propionate $\mathrm{fx} 9$ i-Butyrate. was observed that $\mathrm{pH}$ was around 5, acetate and butyrate were the main VFAs present and hydrogen partial pressure achieved values in the range of $8000-8500 \mathrm{~Pa}$. No significant differences, in terms of VFA, $\mathrm{pH}$, and hydrogen production were found between the batch experiments with and without BES.

High VFA concentration, low $\mathrm{pH}$ and high hydrogen partial pressure are the most likely causes for the inhibition of the anaerobic process. Methanogenesis is inhibited at acidic conditions and, consequently, acetate and hydrogen accumulate in the medium. Furthermore, the anaerobic oxidation of acetate (acetogenesis) only proceeds at low hydrogen partial pressures to favour the thermodynamics of the reactions. Hydrogen partial pressure must be below $10 \mathrm{~Pa}\left(10^{-4} \mathrm{~atm}\right)$ for fatty acid degradation to proceed [22].

The high hydrogen partial pressure observed in the assays with $50 \mathrm{~g}$ COD/L was possibly blocking the degradation of fatty acids. Consequently, acetate and butyrate accumulated, reaching 1.1 and 1.3-1.6 g/L, respectively. Moreover, acetate accumulation can affect the degradation of butyrate and consequently the $\mathrm{pH}$, as referred by Ahring and Westermann [23]. These authors concluded that the accumulation of hydrogen and acetate can inhibit the activity of the acetogenic bacteria that degrade butyrate in syntrophic association with methanogens. They found that increasing hydrogen partial pressure from 100 to $2030 \mathrm{~Pa}$ and acetate concentration from 16.4 to $81.4 \mathrm{mM}$, gradually inhibited butyrate consumption. Siriwongrungson et al. [16] concluded that the reaction of butyrate to acetate and hydrogen under suppressed methanogenic conditions was possible when hydrogen partial pressure was kept at low values.

One of the main concerns in biohydrogen production from wastes is that the activity of hydrogen consuming microorganisms, like methanogenic archaea and homoacetogenic bacteria, must be suppressed. In this study, a concentration of OMW $50 \mathrm{~g}$ COD/L was per si inhibitory for methanogenesis and homoacetogensis, and the activity of hydrogen-producing microorganisms was preserved. The remaining organic matter can be used in a second stage to produce methane which would improve the treatment and the energetic valorization of OMW. This two-stage approach has a potential near-term practical application in the production of biogas enriched with hydrogen. Actually, a mixture of $5-15 \%$ hydrogen in biogas has already been demonstrated to work in internal combustion engines [24]. This hydrogen rich source of biofuel can significantly reduce the emission of $\mathrm{CO}, \mathrm{CO}_{2}$ and $\mathrm{NOx}$.

Table 2 - Volatile fatty acids (VFA), pH and hydrogen partial pressure measured at the end of the BES-free and BES containing batch experiments with $50 \mathrm{~g}$ COD/L of OMW.

\begin{tabular}{llll} 
Parameter & & \multicolumn{1}{c}{ BES-free } & \multicolumn{1}{c}{ BES } \\
\hline VFA $(\mathrm{g} / \mathrm{L})$ & Acetate & $1.13 \pm 0.09$ & $1.06 \pm 0.25$ \\
& Propionate & $0.0 \pm 0.0$ & $0.0 \pm 0.0$ \\
& i-Butyrate & $0.0 \pm 0.0$ & $0.0 \pm 0.0$ \\
& n-Butyrate & $1.56 \pm 0.06$ & $1.30 \pm 0.28$ \\
$\mathrm{pH}$ & $4.9 \pm 0.1$ & $5.0 \pm 0.1$ \\
$\mathrm{H}_{2}$ Partial Pressure $(\mathrm{Pa})$ & $8.0 \mathrm{E} 3$ & $8.5 \mathrm{E} 3$ \\
\hline \multicolumn{2}{l}{ Average \pm standard deviation; $n=4}$. \\
\hline
\end{tabular}


At high OMW concentrations such as, $100 \mathrm{~g}$ COD/L the inhibition is extended to most of the microbial consortium, probably due to the high concentration of complex compounds (lipids and phenolic).

\section{Conclusions}

This study demonstrated that OMW biodegradation to methane and hydrogen, in batch experiments, was determined by its concentration. Hydrogen was consistently produced at OMW concentrations of $50 \mathrm{~g}$ COD/L and methane was produced for concentration in the range of 2-25 g COD/L. In the present study, methanogenesis and homoacetogenesis were naturally inhibited at OMW concentration $\geq 50 \mathrm{~g}$ COD/L. It was possible to recover hydrogen without addition of a synthetic methanogenesis and homoacetogenesis suppressor. However for OMW at $100 \mathrm{~g}$ COD/L neither hydrogen nor methane could be produced.

\section{Acknowledgements}

The authors thank the FCT Strategic Project PEst-OE/EQB/ LA0023/2013, the FCT Project RECI/BBB-EBI/0179/2012, the Project "BioEnv - Biotechnology and Bioengineering for a sustainable world”, REF. NORTE-07-0124-FEDER-000048, co-funded by the Programa Operacional Regional do Norte (ON.2 - O Novo Norte), QREN, FEDER. Also through the project PTDC/ENR/ 69755/2006 and grants given to Marta Gonçalves SFRH/BD/ 40746/2007, José Carlos Costa SFRH/BDP/48962/2008 and Ângela A Abreu SFRH/BPD/82000/2011.

\section{R E F E R E N C E S}

[1] Niaounakis M, Havaldakis CP. Olive processing waste management. Literature review and patent survey. 2nd ed. Oxford: Elsevier; 2006.

[2] Frederici F, Fava F, Kalogerakis N, Mantzavinos D. Valorisation of agro-industrial by-products, effluents and waste: concept, opportunities and the case of olive mil wastewaters. J Chem Technol Biotechnol 2009;84(6):895-900.

[3] Rönnebro E. Development of group II borohydrides as hydrogen storage materials. Curr Opin Solid State Mater Sci 2011;15(2):44-51.

[4] (a)Gonçalves MR, Costa JC, Marques IP, Alves MM. Inoculum acclimation to oleate promotes the conversion of olive mill wastewater to methane. Energy 2011;36(4):2138-41; (b)Gonçalves MR, Costa JC, Marques IP, Alves MM. Strategies for lipids and phenolics degradation in the anaerobic treatment of olive mill wastewater. Water Res 15 April 2012;46(6):1684-92.

[5] Eroglu E, Eroglu I, Gunduz U, Turker L, Yucel M. Biological hydrogen production from olive mil wastewater with twostage processes. Int J Hydrogen Energy 2006;31:1527-35.

[6] Eroglu E, Eroglu I, Gunduz U, Turker L, Yucel M. Treatment of olive mil wastewater by different physicochemical methods and utilization of their liquid effluents for biological hydrogen production. Biomass Bioenergy 2009;33:701-5.

[7] Eroglu E, Eroglu I, Gunduz U, Turker L, Yucel M. Comparison of physicochemical characteristics and photofermentative hydrogen production potential of wastewaters produced from different olive oil mills in Wester-Anatolia, Turkey. Biomass Bioenergy 2009;33:706-11.

[8] Ntaikou I, Kourmentza C, Koutrouli EC, Stamatelatou K, Zampraka A, Kornaros M, et al. Exploitation of olive oil mil wastewater for combined biohydrogen and biopolymers production. Bioresour Technol 2009;100:3724-30.

[9] Lovley DR, Klug MJ. Methanogenesis from methanol and methylamines and acetogenesis from hydrogen and carbondioxide in the Sediments of A Eutrophic Lake. Appl Environ Microbiol 1983;45:1310-5.

[10] Mohan SV, Babu VL, Sarma PN. Effect of various pretreatment methods on anaerobic mixed microflora to enhance biohydrogen production utilizing dairy wastewater as substrate. Bioresour Technol 2008;99:59-67.

[11] Abreu AA, Alves JI, Pereira MA, Sousa DZ, Alves MM. Strategies to suppress hydrogen-consuming microorganisms affect macro and micro scale structure and microbiology of granular sludge. Biotechnol Bioeng 2011;108(8):1766-75.

[12] Xu K, Liu H, Chen J. Effect of classic methanogenic inhibitors on the quantity and diversity of archeal community and the reductive homoacetogenic activity during the process of anaerobic sludge digestion. Bioresour Technol 2010;101:2600-7.

[13] Zinder SH, Anguish T, Cardwell SC. Selective inhibition by 2Bromoethanesulfonate of methanogenesis from acetate in a thermophilic anaerobic digestor. Appl Environ Microbiol 1984;47(6):1343-5.

[14] Chidthaisong A, Conrad R. Specificity of chloroform, 2bromoethanesulfonate and fluoroacetate to inhibit methanogenesis and other anaerobic processes in anoxic rice field soil. Soil Biol Biochem 2000;32:977-88.

[15] Chong M-L, Rahim RA, Shirai Y, Hassan MA. Biohydrogen production by Clostridium butyricum EB6 from palm oil mill effluent. Int J Hydrogen Energy 2009;34:764-71.

[16] Siriwongrungson V, Raymond Z, Angelidaki I. Homoacetogenesis as the alternative pathway for $\mathrm{H}_{2}$ sink during thermophilic anaerobic degradation of butyrate under suppressed methanogenesis. Water Res 2007;41:4204-10.

[17] Luo G, Karakashev D, Xie L, Zhou Q, Angelidaki I. Long-term effect of inoculum pretreatment on fermentative hydrogen production by repeated batch cultivations: homoacetogenesis and methanogenesis as competitors to hydrogen production. Biotechnol Bioeng 2011;108(8):1816-27.

[18] Gonçalves MR, Freitas P, Marques IP. Bioenergy recovery from olive mill effluent in a hybrid reactor. Biomass Bioenergy April 2012;39:253-60.

[19] Schink B. Energetics of syntrophic cooperation in methanogenic degradation. Microbiol Mol Biol Rev 1997;612:262-80.

[20] Ahring BK, Westermann P, Mah RA. Hydrogen inhibition of acetate metabolism and kinetics of hydrogen consumption by Methanosarcina thermophila TM-1. Arch Microbiol 1991;157:38-42.

[21] Beccari M, Bonemazzi F, Majone M, Riccardi C. Interaction between acidogenesis and methanogenesis in the anaerobic treatment of olive oil mill effluents. Water Res 1996;30(1):183-9.

[22] Beccari M, Carucci G, Majone M, Torrisi L. Role of lipids and phenolic compounds in the anaerobic treatment of olive oil mill effluents. Environ Technol 1999;20(1):105-10.

[23] Ahring BK, Westermann P. Product inhibition of butyrate metabolism by acetate and hydrogen in a thermophilic coculture. Appl Environ Microbiol 1988;54(10):2393-7.

[24] Porpatham E, Ramesh A, Nagalingam B. Effect of hydrogen addition on the performance of a biogas fuelled spark ignition engine. Int J Hydrogen Energy 2007;32:2057-65. 